\title{
Antioxidant Responses in Hypertensive Postmenopausal Women after Acute Beetroot Juice Ingestion and Aerobic Exercise: Double Blind and Placebo-Controlled Crossover Trial
}

\author{
Ana Luiza Amaral $\left(\mathbb{D},{ }^{1}\right.$ Igor Moraes Mariano $\left(\mathbb{D},{ }^{1}\right.$ Victor Hugo V. Carrijo $\left(\mathbb{D},{ }^{1}\right.$ \\ Tállita Cristina F. de Souza $\mathbb{D}^{1},{ }^{1}$ Adriele V. de Souza $\mathbb{D}^{2},{ }^{2}$ Douglas C. Caixeta $\mathbb{D}$, \\ Renata R. Teixeira $\mathbb{D}^{2}{ }^{2}$ Erick P. de Oliveira $\mathbb{D}^{3}{ }^{3}$ Foued S. Espindola $\mathbb{D}^{2}{ }^{2}$ \\ and Guilherme Morais Puga $\left.{ }^{1}\right)^{1}$ \\ ${ }^{1}$ Laboratory of Cardiorespiratory and Metabolic Physiology, Federal University of Uberlândia, Uberlândia, MG, Brazil \\ ${ }^{2}$ Laboratory of Biochemistry and Molecular Biology, Institute of Biotechnology, Federal University of Uberlândia, Uberlândia, \\ MG, Brazil \\ ${ }^{3}$ Laboratory of Nutrition, Exercise and Health (LaNES), School of Medicine, Federal University of Uberlandia (UFU), Uberlandia, \\ Minas Gerais, Brazil
}

Correspondence should be addressed to Ana Luiza Amaral; anaribeiro.am@gmail.com and Guilherme Morais Puga; gmpuga@gmail.com

Received 5 February 2021; Revised 25 March 2021; Accepted 2 April 2021; Published 14 April 2021

Academic Editor: Ana Lloret

Copyright @ 2021 Ana Luiza Amaral et al. This is an open access article distributed under the Creative Commons Attribution License, which permits unrestricted use, distribution, and reproduction in any medium, provided the original work is properly cited.

\begin{abstract}
This study is aimed to analyze the effect of different nitrate concentrations $\left[\mathrm{NO}_{3}{ }^{-}\right]$present in beetroot juice (BJ) on salivary oxidative stress markers after acute exercise performance in hypertensive postmenopausal women. Thirteen hypertensive postmenopausal women participated in three experimental sessions, taking different beverages: noncaloric orange flavored drink (OFD), low nitrate (low- $\mathrm{NO}_{3}{ }^{-}$) $\mathrm{BJ}$, and high nitrate (high- $\mathrm{NO}_{3}{ }^{-}$) BJ. The participants performed aerobic exercise on a treadmill, at $65-70 \%$ of heart rate reserve (HRR), for $40 \mathrm{~min}$. Saliva samples were collected after an overnight fast, 10 minutes before BJ ingestion at $7: 20 \mathrm{am}\left(0^{\prime}\right), 120$ minutes after beverages ingestion $\left(130^{\prime}\right)$, immediately after exercise $\left(170^{\prime}\right)$, and $90 \mathrm{~min}$ after exercise $\left(260^{\prime}\right)$. Salivary total protein (TP), catalase activity (CAT), reduced glutathione (GSH), and total antioxidant capacity by ferric-reducing antioxidant power (FRAP) concentrations were analyzed. No interaction (session*time) was found among three sessions over time. Catalase area under the curve (AUC) was lower after both low- $\mathrm{NO}_{3}{ }^{-}$and high- $\mathrm{NO}_{3}{ }^{-}$ consumption $(p<0.001)$, and GSH AUC was lower after high- $\mathrm{NO}_{3}{ }^{-}(p<0.001)$ compared with OFD. So, the acute intake of BJ with aerobic exercise seems to decrease catalase (in high- $\mathrm{NO}_{3}{ }^{-}$and low- $\mathrm{NO}_{3}{ }^{-}$) and $\mathrm{GSH}$ (in high- $\mathrm{NO}_{3}{ }^{-}$), besides not interfering with FRAP in hypertensive postmenopausal women.
\end{abstract}

\section{Introduction}

Postmenopausal hypertensive women have increased cardiovascular risk [1], which is can be caused and/or aggravated by excessive oxidative stress $[2,3]$. Oxidative stress is characterized by the imbalance between prooxidants and antioxidants factors in favor of prooxidants. It can lead to cell damage $[4,5]$ due to excess of reactive oxygen species (ROS) $[4,6]$. ROS are involved in aging, inflammation, and several cardiovascular diseases $[3,4,6,7]$. In postmenopausal women, hypertension is a prevalent risk factors for cardiovascular disease [8], and in these patients, there was an increased antioxidant enzyme production to combat the increasement in ROS [9]. Besides that, postmenopausal estrogen cessation alters the bioavailability of nitric oxide (NO), inflammation, and oxidative stress [10], and in hypertensives, endothelium-derived relaxing factors (e.g., NO) were also altered $[11,12]$.

An important precursor of $\mathrm{NO}$ is nitrate, available from two main sources: through diet and from oxidation by NO 
synthase [13]. Beetroot juice (BJ) is a common beverage that has a high nitrate concentration $[14,15]$. The ingestion of this beverage may generate vasodilation and blood pressure reduction in healthy [16] and hypertensive individuals $[15,17]$. Other nitrate effects include interaction with mitochondrial breathing, metabolic pathways activation, and oxidative stress reduction [13]. In addition, BJ contains antioxidant compounds, like betalain, that reduce linoleate damage and lipid membrane oxidation activated by metmyoglobin and free iron [18]. Besides that, there is evidence of elimination of reactive oxygen and nitrogen species (e.g., superoxide and hydrogen peroxide) and less free radical formation by nitrite action, suggesting nitrate antioxidant effects $[14,19,20]$.

As for nitrate concentration in BJ necessary to perform physiological effects, it is known that plasma, salivary, and urinary nitrate/nitrite increases are dose dependents [21, 22 ], with a peak approximately $2-3 \mathrm{~h}$ after the ingestion. In addition, we observed in hypertensive postmenopausal women that there is a dose-dependent salivary nitrite increase for different nitrate concentrations in BJ [23]. However, different levels of nitrate in BJ have dose-dependent effects on exercise performance [21] but not in hypotensive responses [22, 23], and it is not yet known whether the concentration of nitrate present in $\mathrm{BJ}$ alter oxidative stress.

On the other way, aerobic training is able to increase salivary nitrite, and these values were higher than that of plasma [24]. In a study with sodium nitrate supplementation, an increase in salivary nitrite was observed both 60 minutes after ingestion and after 5 days of supplementation [25]. Some studies have shown an improvement in antioxidant defense $[26,27]$, but acutely, the physical exercise increases prooxidant productions [28, 29]. Thus, in hypertensives, exercises should be prescribed carefully. Therefore, the aim of this study was to analyze the effects of BJ intake with different concentrations of nitrate $\left[\mathrm{NO}_{3}{ }^{-}\right]$on the antioxidant response. Our initial hypothesis was that antioxidant biomarkers would increase acutely with high- $\mathrm{NO}_{3}{ }^{-}$and would not change with beverage without $\mathrm{NO}_{3}{ }^{-}$. For this, we evaluated the salivary levels of nitrite and oxidative stress markers after BJ ingestion and moderate aerobic exercise in hypertensive postmenopausal women.

\section{Material and Methods}

The study was carried out at the Federal University of Uberlândia, Uberlândia, MG, Brazil, between June and September 2018. It was registered at Clinicaltrials.gov (NCT03620227), approved by local Ethics Committee (70104717.0.0000.5152), has been conducted in accordance with the Helsinki Declaration, and all participants signed the consent form.

The sample calculation was performed using G.Power 3.1 , using as main variable the variation of catalase after BJ ingestion and exercise $(-33.18 \pm 35 \mathrm{nmol} / \mathrm{min} / \mathrm{mL})$ [30]. Therefore, we found that the minimum sample should be 12 (power of 0.80 ; effect size of 0.474 ; alpha of $0.05 ; 3$ groups and 4 measures).

The inclusion criteria were hypertensive postmenopausal woman (amenorrhea for at least 12 months and (FSH) $>40$
$\mathrm{mIU} / \mathrm{mL}$ ); between 50 and 70 years old; without hormonal therapy; able to exercise on a treadmill; no history of food allergy, heart attack, stroke, or diabetes mellitus; not being sensitive to nitrate; no $\beta$-blockers user; and not being smoker. The exclusion criteria were inability to carry out the protocol for exercise or juice intolerance or even for not fulfilling/observing the fast.

The intervention began with anamnesis and questionnaire (short version IPAQ). Later, anthropometric measures were taken, which included body mass (electronic scale Filizola, São Paulo, Brazil), height (Sanny fixed stadiometer, São Bernardo do Campo, Brazil), abdominal circumference (Filizola inelastic tape, São Paulo, Brazil), and body composition (biobody impedance Inbody 230, Seoul, South Korea), as previously described [31]. For body composition, the volunteers were instructed not to consume alcohol or caffeine $72 \mathrm{~h}$ before and not to perform vigorous physical activities $24 \mathrm{~h}$ before the exam.

2.1. Study Design. The present study was a crossover, randomized, double blind, and placebo-controlled trial. The flow diagram is shown in Figure 1. The protocol extended for 3 visits over 10-21 days, with a wash-out interval of at least 5 days between sessions. On each visit, the volunteers consume one of the following beverages: $\mathrm{BJ}$ with high nitrate concentration (high- $\mathrm{NO}_{3}^{-}$), BJ with low nitrate concentration (low- $\mathrm{NO}_{3}{ }^{-}$), and orange flavor noncaloric drink without nitrate (OFD). Study participants arrived at the laboratory at 7:00 am and left at 11:40 am. Figure 2 illustrates the experimental design.

The volunteers arrived at the laboratory after $8 \mathrm{~h}$ of overnight fasting. Samples of unstimulated saliva were collected after 20 minutes of rest $\left(0^{\prime}\right)$, immediately before exercise $\left(130^{\prime}\right)$, after exercise $\left(170^{\prime}\right)$, and 90 minutes after the exercise $\left(260^{\prime}\right)$. The beverage intake was performed after 10 minutes of rest, and participants had 15 minutes to consume it.

During the intervention, the volunteers were instructed not to ingest any type of food or liquid, except for water in small quantities. Before all sessions, volunteers went through an interview about their own food/drink consumption in the last $24 \mathrm{~h}$. As they could not consume food/drinks rich in nitrate in the last $24 \mathrm{~h}$, participants received a list of dietary restrictions, that includes green vegetables (amaranth, lettuce, cabbage, spinach, broccoli, celery, cauliflower, chinese radish), beetroot, sausage, salami, ham, turkey breast, coffee, energy drinks, soft drinks, alcoholic beverages, and to avoid mouthwashes.

2.2. Exercise Protocol. The protocol consisted of 40 minutes of moderate continuous aerobic exercise on a treadmill. There were five minutes of warm up and two of cool down. The treadmill speed could reach $5.5 \mathrm{~km} / \mathrm{h}$, and the intensity was imposed by treadmill inclination until the volunteer reached the zone between $65 \%$ and $70 \%$ of $\mathrm{HR}$ (heart rate) reserve (HRR) [32]. To monitoring exercise intensity, a heart rate monitor and a Borg scale [33] were used. Whenever the volunteer's HR entered a nonstipulated HR, the exercise was readjusted. 


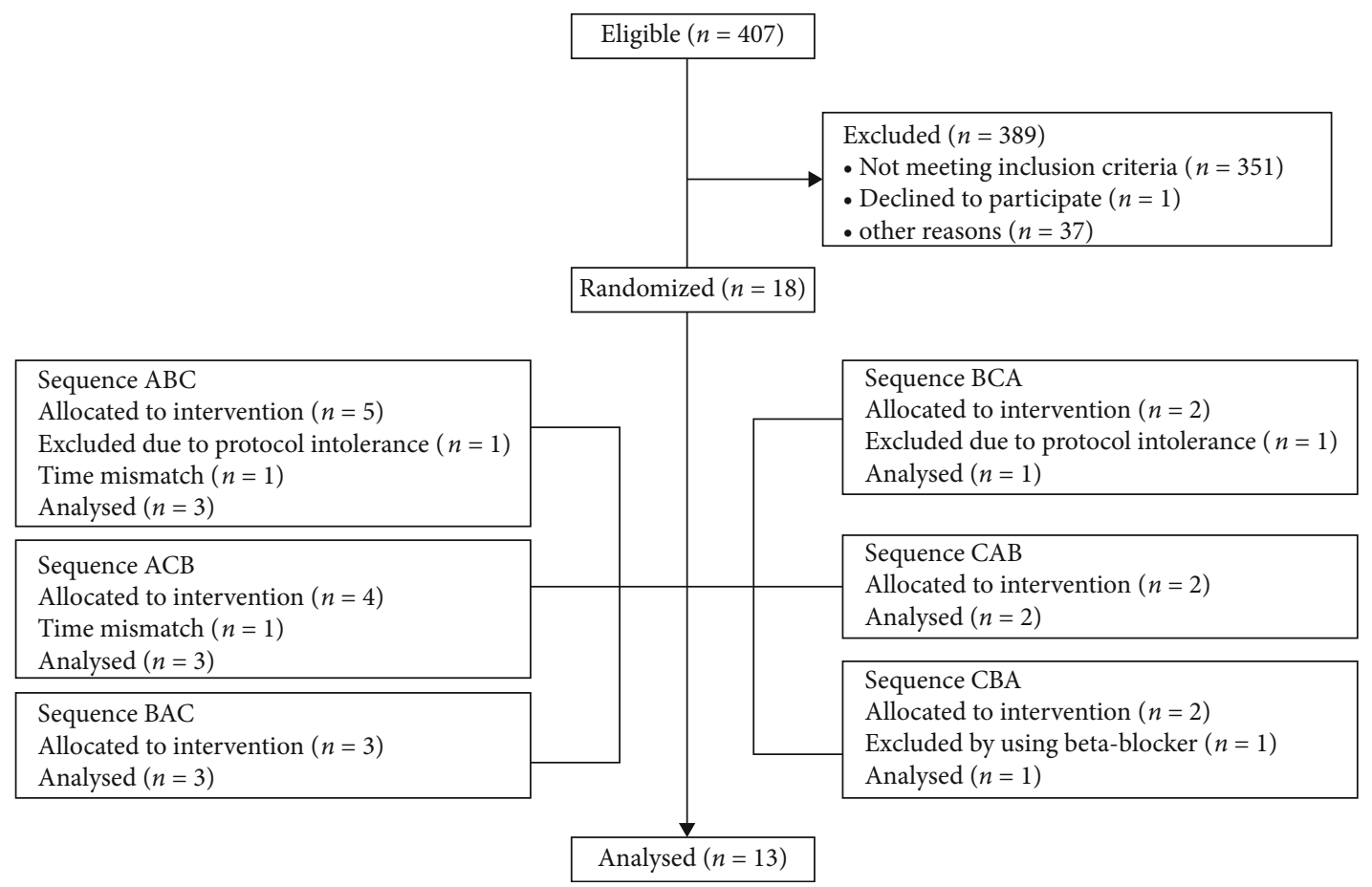

Figure 1: Flow diagram: (A) beetroot juice with low nitrate (low- $\left.\mathrm{NO}_{3}{ }^{-}\right)$; (B) beetroot juice with high nitrate $\left(\right.$high- $\left.\mathrm{NO}_{3}{ }^{-}\right)$; $(\mathrm{C})$ noncaloric orange flavored drink without nitrate (OFD).

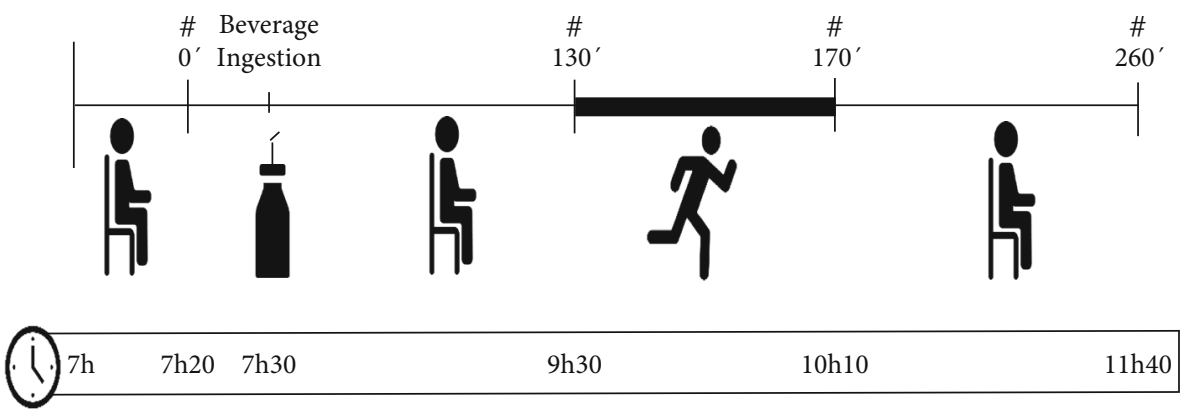

Figure 2: Experimental design of the sessions. (\#) Saliva sample collection.

2.3. Beverage. The protocol was carried out with the ingestion of three different beverages: $\mathrm{OFD}, \mathrm{low}-\mathrm{NO}_{3}{ }^{-}$, and high- $\mathrm{NO}_{3}{ }^{-}$, with one beverage assigned to each session. The beverage intake orders were randomly distributed to each volunteers using a randomization block design through the website (https://www.random.org/lists/). A researcher who did not participate in the data collection was responsible for assigning the codes to each drink and blind them, adding the drink in a bottle with the volunteer's identification.

The high $-\mathrm{NO}_{3}{ }^{-}$had $20.78 \mathrm{mmol} / \mathrm{kg}$ of nitrate and was prepared using $35 \mathrm{~mL}$ of nitrate concentrated BJ (Beet-It Sport Shot, James White Drinks Ltd., Ipswich, UK), which was diluted in $315 \mathrm{~mL}$ of distilled water with $6 \mathrm{~g}$ of noncaloric orange juice flavored powder (Clight, Mondelez International, Inc.), totalizing $350 \mathrm{~mL}$ of juice. The low- $\mathrm{NO}_{3}{ }^{-}$had $3.86 \mathrm{mmol} / \mathrm{kg}$ of nitrate and was prepared by filtering the high- $\mathrm{NO}_{3}{ }^{-}$on an ion exchange resin capable of depleting the nitrate (PA101 OH-, Permution ${ }^{\circledR}$ ) [34], similarly to pre- viously reported $[22,23]$. Lastly, OFD was prepared using $6 \mathrm{~g}$ of orange juice powder diluted in $350 \mathrm{~mL}$ of distilled water. High- $\mathrm{NO}_{3}{ }^{-}$and low $-\mathrm{NO}_{3}{ }^{-}$were identical in taste, while OFD was slightly different. The beverages were delivered to volunteers in a black sealed bottle, with a lid and straw, with no possibility of viewing or even smelling the beverage.

2.4. Salivary Samples. For the saliva samples, the spit method was used [35]. All samples were centrifuged at $3000 \mathrm{rpm}$ for 15 minutes; the supernatant was separated and stored at $-80^{\circ} \mathrm{C}$ until analysis. From this, the following were analyzed: Total protein was performed by the Bradford method and calculated using a bovine serum albumin curve [36]; Catalase activity was based upon hydrogen peroxide decomposition by catalase present in the samples. Samples were mixed with $10 \mathrm{mmol} . \mathrm{L}^{-1}$ potassium phosphate buffer ( $\mathrm{pH}$ 7.0) containing $0.2 \%$ hydrogen peroxide. The hydrogen peroxide decomposition was monitored at $240 \mathrm{~nm}$ for $10 \mathrm{~min}$ [37]; Reduced 
glutathione (GSH) sample was mixed with $185 \mu \mathrm{L}$ of $100 \mathrm{mM}$ sodium phosphate buffer ( $\mathrm{pH} 8.0$ ) containing $5 \mathrm{mM}$ EDTA and $15 \mu \mathrm{L}$ of ortho-phthaldialdehyde $(1 \mathrm{mg} / \mathrm{mL}$ in methanol). The solution was incubated in the dark at room temperature for 15 minutes. Fluorescence was read at $350 \mathrm{~nm}$ (excitation) and $420 \mathrm{~nm}$ (emission). Sample concentrations of GSH were calculated using a standard GSH curve (0.001-0.1 mM) [38]; Total antioxidant capacity by ferricreducing antioxidant power (FRAP) was determined by the capacity of the antioxidants present in saliva samples, to reduce $\mathrm{Fe}^{+3}$ to $\mathrm{Fe}^{+2}$ that is chelated by TPTZ (2,4,6-tris (2pyridyl)-s-triazine) and form the complex $\mathrm{Fe}^{+2}$-TPTZ. This colored complex was read in the spectrophotometer at $593 \mathrm{~nm}$, and the antioxidant activity was determined using an analytical curve, constructed with trolox as standard [37].

2.5. Statistical Analysis. Results are presented as mean \pm standard deviation and 95\% confidence interval. The Shapiro-Wilk test was applied to verify data normality, and GEE (Generalized Estimation Equation) was used to analyze time points and interventions (OFD, low- $\mathrm{NO}_{3}{ }_{3}$, and high- $\mathrm{NO}_{3}{ }^{-}$) differences, using Bonferroni post hoc when necessary. The GEE model was set as Linear or Gamma with Log link based on normality and goodness of fit tests. The area under the curve (AUC) by the trapezoidal method was used to compare the interventions, and a one-way ANOVA was used for AUC comparisons. Effect sizes were present as partial eta squared. Statistical significance was set at $p<0.05$. All analyses were performed using SPSS 20 and GraphPad Prism 6.

\section{Results}

Two volunteers were excluded for inability to adapt to the protocol due to an abrupt decrease in blood pressure followed by syncope 15 minutes after exercise in the first collection session. One of these volunteers had consumed high $-\mathrm{NO}_{3}{ }^{-}$and the other low- $\mathrm{NO}_{3}{ }^{-}$. Then, this study was completed by 13 medicated hypertensive postmenopausal women, with mean age of $58.1 \pm 4.6$ years and body mass index of $27.4 \pm 4.2 \mathrm{~kg} / \mathrm{m}^{2}$.

The IPAQ showed that $15 \%$ was very active, $62 \%$ active, and $13 \%$ irregularly active, and there were no sedentary women. It is worth mentioning that blood pressure and nitrite concentration data from the same sample and intervention have already been published, just like the other general characteristics [23]. In this previous study, we emphasize that, as expected, salivary nitrite over time was different among the beverages (biggest increase in high- $\mathrm{NO}_{3}{ }^{-}$, smooth increase in low- $\mathrm{NO}_{3}{ }^{-}$, and no changes in OFD). In addition, we found an important postexercise hypotension, but BJ intake was not able to potentiate it.

Among the antihypertensive drugs, 46\% (6) used Angiotensin Receptor Blockers plus Diuretic polytherapy, 8\% (1) Angiotensin Converting Enzyme Inhibitor plus Diuretic, 31\% (4) Angiotensin Receptor Blockers, 8\% (1) Diuretic, and 8\% (1) Angiotensin Converting Enzyme Inhibitor. Besides that, $31 \%$ (4) used Levothyroxine and 23\% (3) Statins.
Table 1 shows salivary oxidative stress markers and total protein. No interaction (session* time) was found in the salivary markers. It was possible to verify session effects on catalase (OFD did not change; low- $\mathrm{NO}_{3}{ }^{-}$and high- $\mathrm{NO}_{3}{ }^{-}$ increased) and GSH (high- $\mathrm{NO}_{3}{ }^{-}$increased). Regarding time effects, we found a significant difference in all variables being that in total protein, $170^{\prime}$ was greater than all other time points; in catalase, $170^{\prime}$ it was lower than baseline; in GSH, $130^{\prime}$ and $170^{\prime}$ were greater than baseline; and in FRAP, $130^{\prime}$ and $260^{\prime}$ were lower than baseline, $170^{\prime}$ was bigger than $130^{\prime}$, and $260^{\prime}$ was lower than $170^{\prime}$.

Figure 3 shows the salivary oxidative stress markers over time and their respective AUC. The AUC of salivary catalase activity from both high- $\mathrm{NO}_{3}{ }^{-}$and low- $\mathrm{NO}_{3}{ }^{-}$(Figure 3(b)) were lower $(p<0.01)$ than OFD session. Only salivary GSH AUC from high- $\mathrm{NO}_{3}{ }^{-}$was lower $(p<0.01)$ than OFD session (Figure 2(d)). No difference was found in FRAP AUC among sessions.

\section{Discussion}

Our study investigated if acute BJ ingestion with different nitrate doses could change salivary oxidative stress markers after a moderate aerobic exercise in hypertensive postmenopausal women. The main results were that the antioxidant responses are better in high amounts of nitrate, although we also found a positive effect in catalase in both high- $\mathrm{NO}_{3}{ }^{-}$and low- $\mathrm{NO}_{3}$. Catalase reduced with the intake of high- $\mathrm{NO}_{3}{ }^{-}$and low- $\mathrm{NO}_{3}{ }^{-}$, and postexercise a fall occurs. Besides that, we observed that GSH levels are maintained after high- $\mathrm{NO}_{3}{ }^{-}$, while OFD increases it. Furthermore, exercise does not alter $\mathrm{GSH}$, since before and after exercise sessions were greater than the baseline. After interventions, FRAP reduces when compared to baseline, but high- $\mathrm{NO}_{3}{ }^{-}$or low- $-\mathrm{NO}_{3}{ }^{-}$does not differ in their responses in relation to OFD.

Acute BJ ingestion with high doses of nitrate has been studied as potential antioxidant. These effects occur because nitrate is an important precursor of NO [21], and beetroot contains antioxidant nutrients, like polyphenoid compounds, and free radical scavengers $[14,18,39]$. In vitro [40], it was observed that a shot of BJ manages to supply a large number of bioaccessible antioxidants in gastric and duodenal cells, hypothesizing that this would be an interesting strategy to increase the body's antioxidant status. Some authors showed, in a study with diet control over four weeks of BJ [41], an increase in lipid peroxidation, indicating a change in oxidative behavior.

In this sense, in a previous study [23] with similar beverages and population, we found an increase in salivary nitrite with high- $\mathrm{NO}_{3}{ }^{-}$, but there was no potentiation of postexercise hypotension. In addition, in a systematic review [42], it is commented that $\mathrm{BJ}$ is rich in antioxidants that suppress the accumulation of leukocytes after exercise, reducing muscle damage and that the betalain present in beetroot is able to attenuate muscle damage by analgesic and anti-inflammatory effects.

Our results showed that the catalase activity decreased after exercise in both high- $\mathrm{NO}_{3}{ }^{-}$and low- $\mathrm{NO}_{3}{ }^{-}$, and this 
TABLE 1: Salivary oxidative stress markers and total protein, at baseline $\left(0^{\prime}\right)$, two hours after beetroot juice consume, and immediately before exercise $\left(130^{\prime}\right)$, immediately postexercise $\left(170^{\prime}\right)$, and $90^{\prime}$ postexercise $\left(260^{\prime}\right)$.

\begin{tabular}{|c|c|c|c|c|c|c|c|c|c|}
\hline & $0^{\prime}$ & $130^{\prime}$ & $170^{\prime}$ & $260^{\prime}$ & $p$ session & $p$ time & $p$ session $*$ time & ES & $95 \% \mathrm{CI}$ \\
\hline \multicolumn{10}{|c|}{ Total protein $(\mu \mathrm{g} / \mu \mathrm{L})$} \\
\hline OFD & $0.68 \pm 0.23$ & $0.74 \pm 0.54$ & $0.94 \pm 0.64$ & $0.74 \pm 0.22$ & \multirow{3}{*}{0.166} & \multirow{3}{*}{$<0.001$} & \multirow{3}{*}{0.353} & \multirow{3}{*}{0.102} & \multirow{3}{*}{$0.65 ; 0.76$} \\
\hline Low- $\mathrm{NO}_{3}^{-}$ & $0.74 \pm 0.25$ & $0.68 \pm 0.26$ & $1.24 \pm 0.97$ & $0.65 \pm 0.18$ & & & & & \\
\hline High- $\mathrm{NO}_{3}^{-}$ & $0.74 \pm 0.41$ & $0.62 \pm 0.21$ & $0.98 \pm 0.81$ & $0.68 \pm 0.21$ & & & & & \\
\hline \multicolumn{10}{|c|}{ Catalase $(\mathrm{U} / \mu \mathrm{g}$ prot $)$} \\
\hline OFD & $16.4 \pm 10.3$ & $17.6 \pm 11.0$ & $14.4 \pm 7.2$ & $17.8 \pm 8.2$ & \multirow{3}{*}{$<0.001$} & \multirow{3}{*}{$<0.001$} & \multirow{3}{*}{0.412} & \multirow{3}{*}{0.092} & \multirow{3}{*}{$10.71 ; 14.80$} \\
\hline Low- $\mathrm{NO}_{3}^{-}$ & $17.5 \pm 11.9$ & $10.1 \pm 6.8$ & $7.5 \pm 5.3$ & $12.9 \pm 6.8$ & & & & & \\
\hline High- $\mathrm{NO}_{3}^{-}$ & $16.1 \pm 12.8$ & $10.7 \pm 7.7$ & $7.4 \pm 5.2$ & $12.1 \pm 9.0$ & & & & & \\
\hline \multicolumn{10}{|c|}{ GSH (nmol/mg prot) } \\
\hline OFD & $31.6 \pm 20.3$ & $46.0 \pm 29.6$ & $42.7 \pm 20.2$ & $35.3 \pm 11.6$ & \multirow{3}{*}{0.040} & \multirow{3}{*}{0.004} & \multirow{3}{*}{0.217} & \multirow{3}{*}{0.091} & \multirow{3}{*}{$29.65 ; 36.47$} \\
\hline Low- $\mathrm{NO}_{3}^{-}$ & $25.9 \pm 9.3$ & $40.9 \pm 22.4$ & $33.5 \pm 13.7$ & $41.5 \pm 19.6$ & & & & & \\
\hline High- $\mathrm{NO}_{3}^{-}$ & $27.5 \pm 13.3$ & $38.5 \pm 35.0$ & $37.0 \pm 26.4$ & $29.9 \pm 15.3$ & & & & & \\
\hline \multicolumn{10}{|c|}{ FRAP (nmol Trolox) } \\
\hline OFD & $54.9 \pm 30.2$ & $44.5 \pm 34.3$ & $53.4 \pm 20.4$ & $46.4 \pm 22.2$ & \multirow{3}{*}{0.098} & \multirow{3}{*}{$<0.001$} & \multirow{3}{*}{0.680} & \multirow{3}{*}{0.055} & \multirow{3}{*}{$43.28 ; 54.54$} \\
\hline Low- $\mathrm{NO}_{3}^{-}$ & $61.5 \pm 34.8$ & $43.1 \pm 20.8$ & $63.6 \pm 23.1$ & $49.8 \pm 30.7$ & & & & & \\
\hline High- $\mathrm{NO}_{3}{ }^{-}$ & $59.0 \pm 32.4$ & $42.5 \pm 29.7$ & $52.3 \pm 32.7$ & $45.8 \pm 29.3$ & & & & & \\
\hline
\end{tabular}

Mean \pm standard deviation of salivary markers. ES: effect size (partial eta squared); CI: confidence interval; GSH: reduced glutathione; FRAP: ferric reducing ability of plasma; OFD: noncaloric orange flavored drink without nitrate; low- $\mathrm{NO}_{3}{ }^{-}$: beetroot juice with low nitrate; high- $\mathrm{NO}_{3}$ : beetroot juice with high nitrate; $0^{\prime}$ : salivary sample at rest; $130^{\prime}$ : salivary sample before aerobic exercise; $170^{\prime}$ : salivary sample after aerobic exercise; $260^{\prime}$ : salivary sample $90^{\prime}$ after aerobic exercise.

shows that possibly nitrate had no effect (or had a partial effect) on this antioxidant enzyme, but what may have reduced this enzyme are other antioxidant substances present in BJ. This enzyme acts as the first defense line against oxidative stress [43]. One of its functions is to catalyze the degradation/reduction of hydrogen peroxide [43]. Hydrogen peroxide in high concentrations is harmful to cells and is related to the pathophysiology of hypertension [44]. There is evidence that catalase production increases with the presence of ROS; however, with the presence of beet leaf extract, its levels are restored to baseline [45]. It was noticed that catalase responses by postintense exercise in amateur athletes there is an increase in its bioavailability for up to $24 \mathrm{~h}$ postexercise. In heart failure patients [46], post 30 minutes of moderate exercise, there is a catalase increase, but after low-intensity exercise with greater volume (45 minutes), there is a reduction in this enzyme. Which may indicate that the exercise intensity is more related to the oxidative stress than the volume. Regarding the ingestion of BJ, in athletes [30], the catalase activity increased after interval exercise, with no difference with placebo, distinguishing from the present study, in which the catalase activity reduced similarly between high- $\mathrm{NO}_{3}{ }^{-}$and low $-\mathrm{NO}_{3}{ }^{-}$.

Another important endogenous antioxidant is GSH, which is involved in cellular protection against excessive oxidative stress both directly and as an enzymatic cofactor of glutathione peroxidases [47]. This is an antioxidant molecule oxidized by glutathione peroxidase, an intracellular enzyme capable of reducing hydrogen peroxide with an important role in inhibiting the lipid peroxidation [43]. Our results showed that salivary GSH concentration decreases only after high- $\mathrm{NO}_{3}{ }^{-}$. In addition to betanine, beetroot is also rich in polyphenoid compounds, such as ascorbic acid, carotenoids, phenolic acids, flavonoids [48], and bioactive betalain [49], all of which are potential antioxidants [40]. This may indicate that the antioxidants present in beetroots increase GSH, although the difference with placebo was observed only with high- $\mathrm{NO}_{3}{ }^{-}$, which shows that nitrate also plays an important role. Unlike the present study, in a study with 7 days intake of 2 shots with $6.5 \mathrm{mmol}$ of $\mathrm{NO}_{3}{ }^{-} \mathrm{BJ}$ per day with active and healthy young men [50], no changes were found in GSH, which may indicate that chronical beverage intake, with double nitrate concentration in two doses per day, does not modify these responses in a healthy population. When verifying these responses in intense exercise in amateur athletes [51], GSH did not undergo any changes within $72 \mathrm{~h}$ after exercise. However, when we observe these responses postmoderate resistance exercise with active young men [52], there is an increase in plasma GSH but without differences in salivary analysis, which may indicate greater sensitivity of blood analysis. From our results, we realized that a high- $\mathrm{NO}_{3}{ }^{-}$reduces $\mathrm{GSH}$, probably due to the presence of a high dose of nitrate related to the presence of antioxidants and other components, such as high levels of GSH and other antioxidant molecules not evaluated here.

The last variable analyzed was FRAP, which aims to analyze the antioxidant power [53]. In vitro [40], with the same BJ from the present study, an increase in FRAP was found after the gastric phase, with a marked reduction after the duodenal phase, which may be related to the 


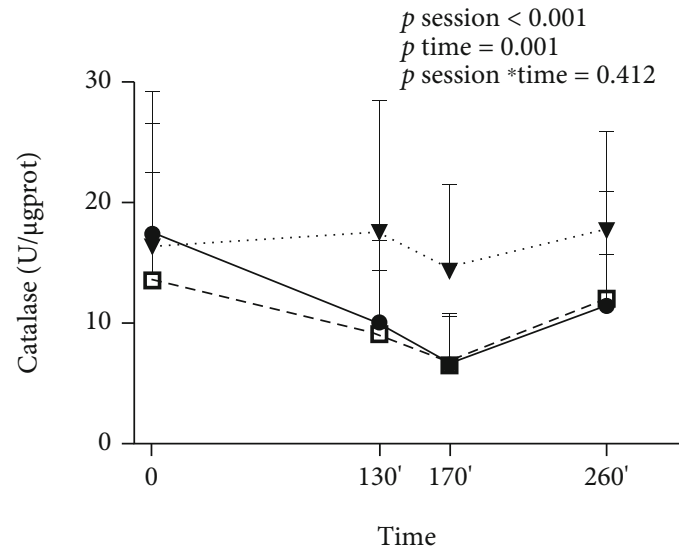

(a)

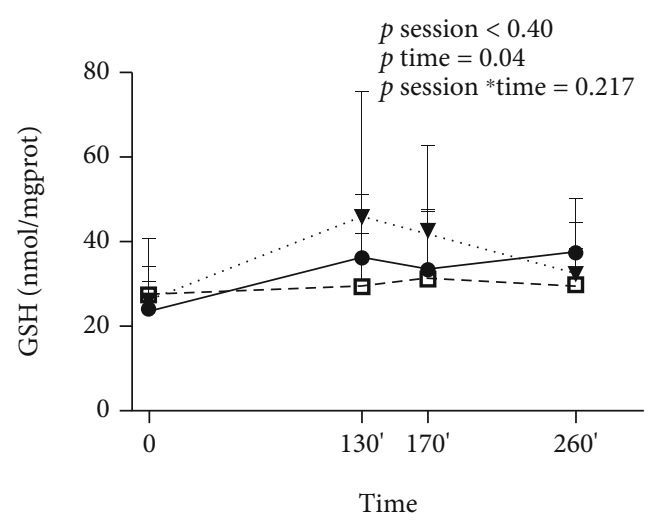

(c)

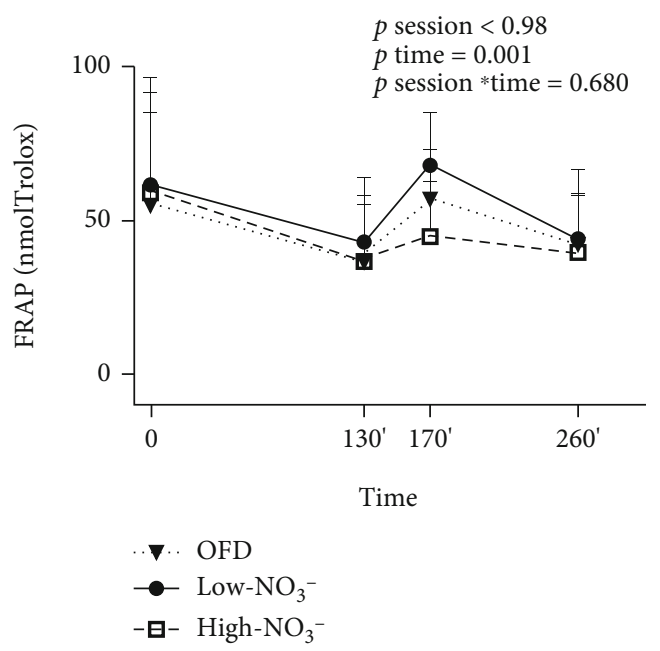

(e)

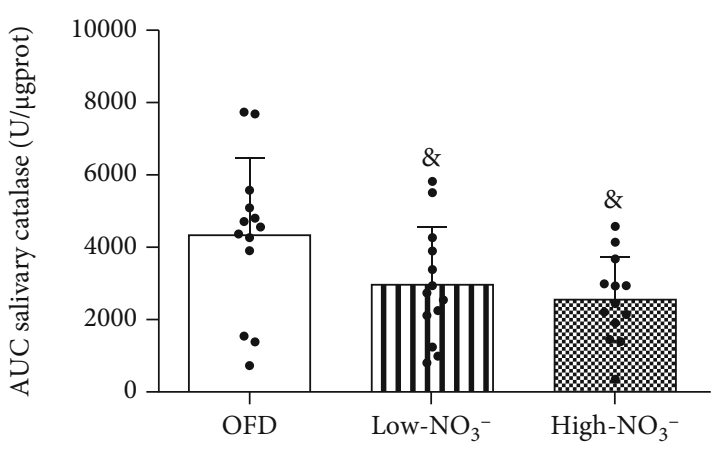

(b)

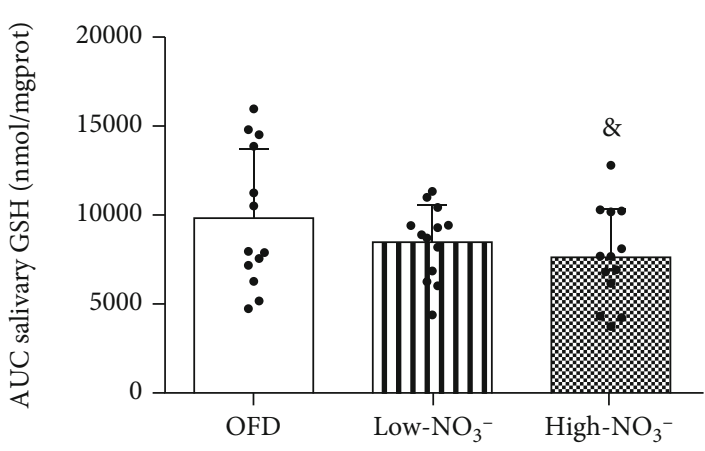

(d)

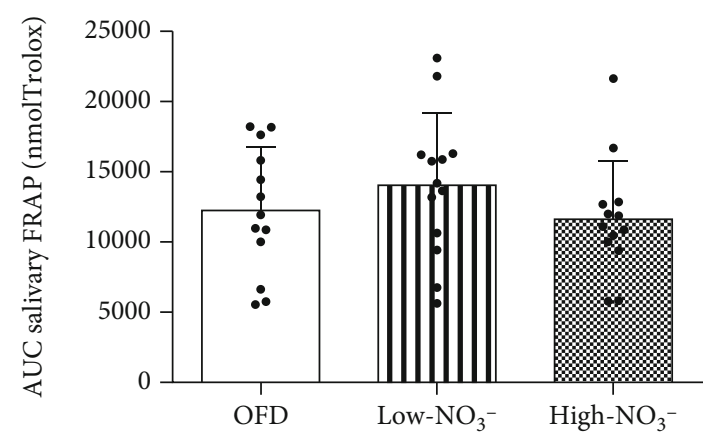

(f)

FIgURE 3: Salivary oxidative stress markers and AUC. Mean \pm standard deviation of salivary oxidative stress markers. $0^{\prime}$ : fasting rest collection; $130^{\prime}$ : two hours after BJ consumption and immediately before aerobic exercise; $170^{\prime}$ : immediately after aerobic exercise; $260^{\prime}$ : 90 minutes after the aerobic exercise session; GSH: reduced glutathione; FRAP: total antioxidant capacity by ferric-reducing antioxidant power. \&: $p<0.05$ vs. OFD.

biotransformation of antioxidants caused by enzymes interactions. In a review study [14], it is argued that FRAP increases after $\mathrm{BJ}$ ingestion, contrary to our findings since in the present study there were no differences between drinks. It is worth noting that, although we found $p<0.001$ in AUC, there was no significant value in the post hoc analysis. We have found no clinical study that analyzed FRAP associated with BJ intake, but in hypertensives, there is evidence of less production when compared with normotensive individuals $[54,55]$. In addition, negative correlations 
were found with systolic and diastolic blood pressures [55], suggesting a role of plasma antioxidant status in modulating blood pressure.

As for the present study, we found a reduction in FRAP after the beverages and 90 minutes postphysical exercise. In trained healthy men [37], FRAP increased after continuous exercise and decreased $3 \mathrm{~h}$ postexercise. These results corroborate our findings, considering that with the beverages intake, there were reductions in FRAP, followed by increases caused by physical exercise, returning to the preexercise values 90 minutes after same. In addition, in physically active men [25], no FRAP modification was found associating sodium nitrate supplementation with 30 minutes of moderate aerobic exercise. This suggests that supplementations of dissociated nitrate from other compounds (such in BJ) may interfere with these responses.

In addition to the intervention characteristics, we must consider that the sample was composed by drug-controlled hypertensive women. We observed that $92 \%$ (12) of the volunteers used drugs that act on the renin-angiotensin system. In this sense, AT1 receptor antagonists or ACE inhibitors may have antioxidant actions by improving endothelial function [56] and reducing ROS production by reducing NADPH oxidase and regulating $\mathrm{Cu} / \mathrm{ZnSOD}$ [57]. It is worth mentioning that since physical exercise was prescribed based on heart rate; we did not include $\beta$-blocking drug users. Another important point is the use of salivary evaluation as a way of analyzing the antioxidant profile. The antioxidant profile of saliva was similar to that of plasma [37], suggesting that as an alternative and noninvasive tool. So, saliva may be an interesting method for studying antioxidants in sports medicine.

Among the limitations of our study, we have the use of antihypertensive drugs, since these drugs can perform specific actions not analyzed. To minimize these effects, we indicated that the volunteers marked the time of day that they used the medication. In addition, with this study, we assessed only the acute effects of BJ intake, and we did not assess its isolated effects (without exercise). We also did not carry out the dietary control of these volunteers, but as a way of minimizing this, they should follow a restriction food list. In addition, we have not evaluated several other antioxidant enzymes, which could give a better oxidant profile. These results can be applied specifically to hypertensive postmenopausal women and cannot be stratified for other populations.

As a clinical application, we realized the use of $\mathrm{BJ}$ as a treatment for hypertension has been studied in recent years [58]. Since there are discussions about the increase in hypertension incidence, especially low- and middleincome countries [59], We believe that this study can contribute to finding food benefits that are already present in the population's diet and can be used to add knowledge to alternative treatments of hypertension.

\section{Conclusion}

We conclude that the acute intake of $\mathrm{BJ}$ associated with moderate-intensity aerobic exercise seems to decrease catalase activity (in high- $\mathrm{NO}_{3}^{-}$and low- $\mathrm{NO}_{3}^{-}$) and GSH (in high- $\mathrm{NO}_{3}{ }^{-}$), besides not interfering with FRAP in hypertensive postmenopausal women. Thus, BJ may have positive effects on oxidative stress markers independent of nitrate concentration, although high $-\mathrm{NO}_{3}{ }^{-}$can have smooth better results.

\section{Data Availability}

The general characteristics and oxidative stress data used to support the findings of this study are available from the corresponding author upon request.

\section{Conflicts of Interest}

The authors declare no conflict of interest.

\section{Acknowledgments}

This study was funded by the Minas Gerais State Research Foundation (FAPEMIG) (APQ-01874-18) and financed in part by the Coordenação de Aperfeiçoamento de Pessoal de Nível Superior-Brasil (CAPES)_Finance Code 001.

\section{References}

[1] R. M. R. Meirelles, "Menopause and metabolic syndrome," Arquivos Brasileiros de Endocrinologia \& Metabologia, vol. 58, no. 2, pp. 91-96, 2014.

[2] S. S. Signorelli, S. Neri, S. Sciacchitano et al., "Behaviour of some indicators of oxidative stress in postmenopausal and fertile women," Maturitas, vol. 53, no. 1, pp. 77-82, 2006.

[3] T. Senoner and W. Dichtl, "Oxidative stress in cardiovascular diseases: still a therapeutic target?," Nutrients, vol. 11, no. 9, p. 2090, 2019.

[4] H. Sies, C. Berndt, and D. P. Jones, "Oxidative stress," Annual Review of Biochemistry, vol. 86, no. 1, pp. 715-748, 2017.

[5] J. Papaconstantinou, "The role of signaling pathways of inflammation and oxidative stress in development of senescence and aging phenotypes in cardiovascular disease," Cells, vol. 8, no. 11, p. 1383, 2019.

[6] H. Sies, "Biochemistry of oxidative stress," Angewandte Chemie International Edition in English, vol. 25, no. 12, pp. 1058-1071, 1986.

[7] D. H. Endemann and E. L. Schiffrin, "Endothelial dysfunction," Journal of the American Society of Nephrology, vol. 15, no. 8, pp. 1983-1992, 2004.

[8] M. Malachias, W. Souza, F. Plavnik et al., "7a Diretriz Brasileira de Hipertensão Arterial: Capítulo 1-Conceituação, Epidemiologia e Prevenção Primária," Arquivos Brasileiros de Cardiologia, vol. 107, no. 3, pp. 1-6, 2016.

[9] L. Cavas, P. Arpinar, and K. Yurdakoc, "Possible interactions between antioxidant enzymes and free sialic acids in saliva: a preliminary study on elite judoists," International Journal of Sports Medicine, vol. 26, no. 10, pp. 832-835, 2005.

[10] S. Witkowski and C. Serviente, "Endothelial dysfunction and menopause: is exercise an effective countermeasure?," Climacteric, vol. 21, no. 3, pp. 267-275, 2018.

[11] Y. Higashi, T. Maruhashi, K. Noma, and Y. Kihara, "Oxidative stress and endothelial dysfunction: clinical evidence and therapeutic implications," Trends in Cardiovascular Medicine, vol. 24, no. 4, pp. 165-169, 2014. 
[12] A. Bielli, M. G. Scioli, D. Mazzaglia, E. Doldo, and A. Orlandi, "Antioxidants and vascular health," Life Sciences, vol. 143, pp. 209-216, 2015.

[13] J. O. Lundberg, M. Carlström, and E. Weitzberg, "Metabolic effects of dietary nitrate in health and disease," Cell Metabolism, vol. 28, no. 1, pp. 9-22, 2018.

[14] T. Clifford, G. Howatson, D. J. West, and E. J. Stevenson, "The potential benefits of red beetroot supplementation in health and disease," Nutrients, vol. 7, no. 4, pp. 2801-2822, 2015.

[15] C. P. Kerley, E. Dolan, and L. Cormican, "Nitrate-rich beetroot juice selectively lowers ambulatory pressures and LDL cholesterol in uncontrolled but not controlled hypertension: a pilot study," Irish Journal of Medical Science, vol. 186, no. 4, pp. 895-902, 2017.

[16] A. J. Webb, N. Patel, S. Loukogeorgakis et al., “Acute blood pressure lowering, vasoprotective, and antiplatelet properties of dietary nitrate via bioconversion to nitrite," Hypertension, vol. 51, no. 3, pp. 784-790, 2008.

[17] V. Kapil, R. S. Khambata, A. Robertson, M. J. Caulfield, and A. Ahluwalia, "Dietary nitrate provides sustained blood pressure lowering in hypertensive patients: a randomized, phase 2, double-blind, placebo-controlled study," Hypertension, vol. 65, no. 2, pp. 320-327, 2015.

[18] J. Kanner, S. Harel, and R. Granit, "BetalainsA new class of dietary cationized antioxidants," Journal of Agricultural and Food Chemistry, vol. 49, no. 11, pp. 5178-5185, 2001.

[19] J. O. Lundberg, M. Carlström, F. J. Larsen, and E. Weitzberg, "Roles of dietary inorganic nitrate in cardiovascular health and disease," Cardiovascular Research, vol. 89, no. 3, pp. 525-532, 2011.

[20] D. A. Wink, K. M. Miranda, M. G. Espey et al., "Mechanisms of the antioxidant effects of nitric oxide," Antioxidants \& Redox Signaling, vol. 3, no. 2, pp. 203-213, 2001.

[21] L. J. Wylie, J. Kelly, S. J. Bailey et al., "Beetroot juice and exercise: pharmacodynamic and dose-response relationships," Journal of Applied Physiology, vol. 115, no. 3, pp. 325-336, 2013.

[22] C. P. Bondonno, A. H. Liu, K. D. Croft et al., "Absence of an effect of high nitrate intake from beetroot juice on blood pressure in treated hypertensive individuals: a randomized controlled trial," The American Journal of Clinical Nutrition, vol. 102, no. 2, pp. 368-375, 2015.

[23] A. L. Amaral, I. M. Mariano, V. H. V. Carrijo et al., "A single dose of beetroot juice does not change blood pressure response mediated by acute aerobic exercise in hypertensive postmenopausal women," Nutrients, vol. 11, no. 6, p. 1327, 2019.

[24] M. M. Díaz Gómez, O. L. Bocanegra Jaramillo, R. R. Teixeira, and F. S. Espindola, "Salivary surrogates of plasma nitrite and catecholamines during a 21-week training season in swimmers," PLoS One, vol. 8, no. 5, article e64043, 2013.

[25] E. F. Menezes, L. G. Peixoto, R. R. Teixeira, A. B. Justino, G. M. Puga, and F. S. Espindola, "Potential benefits of nitrate supplementation on antioxidant defense system and blood pressure responses after exercise performance," Oxidative Medicine and Cellular Longevity, vol. 2019, Article ID 7218936, 10 pages, 2019.

[26] J. N. Cobley, P. R. Moult, J. G. Burniston, J. P. Morton, and G. L. Close, "Exercise improves mitochondrial and redoxregulated stress responses in the elderly: better late than never!," Biogerontology, vol. 16, no. 2, pp. 249-264, 2015.
[27] B. Franzke, B. Schober-Halper, M. Hofmann et al., "Age and the effect of exercise, nutrition and cognitive training on oxidative stress - the Vienna Active Aging Study (VAAS), a randomized controlled trial," Free Radical Biology and Medicine, vol. 121, pp. 69-77, 2018.

[28] Y. Hitomi, S. Watanabe, T. Kizaki et al., "Acute exercise increases expression of extracellular superoxide dismutase in skeletal muscle and the aorta," Redox Report, vol. 13, no. 5, pp. 213-216, 2008.

[29] T. Kawamura and I. Muraoka, "Exercise-induced oxidative stress and the effects of antioxidant intake from a physiological viewpoint," Antioxidants, vol. 7, no. 9, p. 119, 2018.

[30] C. R. Carriker, P. Rombach, B. M. Stevens, R. A. Vaughan, and A. L. Gibson, "Acute dietary nitrate supplementation does not attenuate oxidative stress or the hemodynamic response during submaximal exercise in hypobaric hypoxia," Applied Physiology, Nutrition, and Metabolism, vol. 43, no. 12, pp. 1268-1274, 2018.

[31] C. D. Barbosa, J. G. Costa, J. S. Giolo et al., "Isoflavone supplementation plus combined aerobic and resistance exercise do not change phase angle values in postmenopausal women: A randomized placebo- controlled clinical trial," Experimental Gerontology, vol. 117, pp. 31-37, 2019.

[32] M. J. Karvonen, E. Kentala, and O. Mustala, "The effects of training on heart rate; a longitudinal study," Annales Medicinae Experimentalis et Biologiae Fenniae, vol. 35, no. 3, pp. 307-315, 1957, http://www.ncbi.nlm.nih.gov/pubmed/ 13470504.

[33] G. A. Borg, "Psychophysical bases of perceived exertion," Medicine and Science in Sports and Exercise, vol. 14, no. 5, pp. 377381, 1982, http://www.ncbi.nlm.nih.gov/pubmed/7154893.

[34] T. F. de Castro, F. A. Manoel, D. H. Figueiredo, D. H. Figueiredo, and F. A. Machado, "Effect of beetroot juice supplementation on $10-\mathrm{km}$ performance in recreational runners," Applied Physiology, Nutrition, and Metabolism, vol. 44, no. 1, pp. 90-94, 2019.

[35] M. Navazesh, "Methods for collecting saliva," Annals of the New York Academy of Sciences, vol. 694, no. 1 Saliva as a D, pp. 72-77, 1993.

[36] A. B. Justino, R. R. Teixeira, L. G. Peixoto, O. L. B. Jaramillo, and F. S. Espindola, "Effect of saliva collection methods and oral hygiene on salivary biomarkers," Scandinavian Journal of Clinical and Laboratory Investigation, vol. 77, no. 6, pp. 415-422, 2017.

[37] A. V. Souza, J. S. Giolo, R. R. Teixeira et al., "Salivary and plasmatic antioxidant profile following continuous, resistance, and high-intensity interval exercise: Preliminary Study," Oxidative Medicine and Cellular Longevity, vol. 2019, 10 pages, 2019.

[38] R. R. Teixeira, A. V. de Souza, L. G. Peixoto et al., "Royal jelly decreases corticosterone levels and improves the brain antioxidant system in restraint and cold stressed rats," Neuroscience Letters, vol. 655, pp. 179-185, 2017.

[39] T. Esatbeyoglu, A. E. Wagner, R. Motafakkerazad, Y. Nakajima, S. Matsugo, and G. Rimbach, "Free radical scavenging and antioxidant activity of betanin: electron spin resonance spectroscopy studies and studies in cultured cells," Food and Chemical Toxicology, vol. 73, pp. 119-126, 2014.

[40] P. C. Wootton-Beard and L. Ryan, "A beetroot juice shot is a significant and convenient source of bioaccessible antioxidants," Journal of Functional Foods, vol. 3, no. 4, pp. 329$334,2011$. 
[41] L. Kozłowska, O. Mizera, J. Gromadzińska et al., "Changes in oxidative stress, inflammation, and muscle damage markers following diet and beetroot juice supplementation in elite fencers," Antioxidants, vol. 9, no. 7, p. 571, 2020.

[42] D. Rojas-Valverde, J. Montoya-Rodríguez, C. Azofeifa-Mora, and B. Sanchez-Urena, "Effectiveness of beetroot juice derived nitrates supplementation on fatigue resistance during repeated-sprints: a systematic review," Critical Reviews in Food Science and Nutrition, pp. 1-12, 2020.

[43] O. M. Ighodaro and O. A. Akinloye, "First line defence antioxidants-superoxide dismutase (SOD), catalase (CAT) and glutathione peroxidase (GPX): their fundamental role in the entire antioxidant defence grid," Alexandria Journal of Medicine, vol. 54, no. 4, pp. 287-293, 2018.

[44] A. Agita and M. T. Alsagaff, "Inflammation, immunity, and hypertension," Acta Medica Indonesiana, vol. 49, no. 2, pp. 158-165, 2017.

[45] L. G. S. da Silva, A. P. Morelli, I. C. B. Pavan et al., "Protective effects of beet (Beta vulgaris) leaves extract against oxidative stress in endothelial cells in vitro," Phytotherapy Research, vol. 34, no. 6, pp. 1385-1396, 2020.

[46] G. A. Ribeiro-Samora, L. A. Rabelo, A. C. C. Ferreira et al., "Inflammation and oxidative stress in heart failure: effects of exercise intensity and duration," Brazilian Journal of Medical and Biological Research, vol. 50, no. 9, pp. e6393-e6398, 2017.

[47] A. Pompella, A. Visvikis, A. Paolicchi, V. De Tata, and A. F. Casini, "The changing faces of glutathione, a cellular protagonist," Biochemical Pharmacology, vol. 66, no. 8, pp. 1499-1503, 2003.

[48] T. Kujala, M. Vienola, K. Klika, J. Loponen, and K. Pihlaja, "Betalain and phenolic compositions of four beetroot (Beta vulgaris) cultivars," European Food Research and Technology, vol. 214, no. 6, pp. 505-510, 2002.

[49] V. G. Georgiev, J. Weber, E.-M. Kneschke, P. N. Denev, T. Bley, and A. I. Pavlov, "Antioxidant activity and phenolic content of betalain extracts from intact plants and hairy root cultures of the red beetroot Beta vulgaris cv. Detroit dark red," Plant Foods for Human Nutrition, vol. 65, no. 2, pp. 105-111, 2010.

[50] J. Whitfield, D. Gamu, G. J. F. Heigenhauser et al., "Beetroot juice increases human muscle force without changing $\mathrm{Ca} 2$ +-handling proteins," Medicine and Science in Sports and Exercise, vol. 49, no. 10, pp. 2016-2024, 2017.

[51] A. L. Bessa, V. N. Oliveira, G. Agostini et al., "Exercise intensity and Recovery," Journal of Strength and Conditioning Research, vol. 30, no. 2, pp. 311-319, 2016.

[52] R. Deminice, T. Sicchieri, P. O. Payão, and A. A. Jordão, "Blood and salivary oxidative stress biomarkers following an acute session of resistance exercise in humans," International Journal of Sports Medicine, vol. 31, no. 9, pp. 599-603, 2010.

[53] I. F. Benzie and J. J. Strain, "The Ferric Reducing Ability of Plasma (FRAP) as a Measure of "Antioxidant Power": The FRAP Assay," Analytical Biochemistry, vol. 239, no. 1, pp. 70-76, 1996.

[54] M. K. Verma, A. Jaiswal, P. Sharma, P. Kumar, and A. Narayan Singh, "Oxidative stress and biomarker of TNF- $\alpha$, MDA and FRAP in hypertension," Journal of Medicine and Life, vol. 12, no. 3, pp. 253-259, 2019.
[55] R. Rodrigo, H. Prat, W. Passalacqua, J. Araya, C. Guichard, and J. P. Bächler, "Relationship between oxidative stress and essential hypertension," Hypertension Research, vol. 30, no. 12, pp. 1159-1167, 2007.

[56] M. Hermann, A. Flammer, and T. F. Lscher, "Nitric oxide in hypertension," The Journal of Clinical Hypertension, vol. 8, 12 Suppl 4, pp. 17-29, 2006.

[57] M. Tanaka, S. Umemoto, S. Kawahara et al., "Angiotensin II type 1 receptor antagonist and angiotensin-converting enzyme inhibitor altered the activation of $\mathrm{Cu} / \mathrm{Zn}$-containing superoxide dismutase in the heart of stroke-prone spontaneously hypertensive rats," Hypertension Research, vol. 28, no. 1, pp. 67-77, 2005.

[58] M. Siervo, J. Lara, I. Ogbonmwan, and J. C. Mathers, "Inorganic nitrate and beetroot juice supplementation reduces blood pressure in adults: a systematic review and meta-analysis," The Journal of Nutrition, vol. 143, no. 6, pp. 818-826, 2013.

[59] D. J. Hoffman, "Use of beetroot juice extract for hypertension treatment in low- and middle-income countries," The Journal of Nutrition, vol. 150, no. 9, pp. 2233-2234, 2020. 